\title{
Lateralization of the Avian Magnetic Compass: Analysis of Its Early Plasticity
}

\author{
Dennis Gehring ${ }^{1}$, Onur Güntürkün ${ }^{2,3}$, Wolfgang Wiltschko ${ }^{1}$ and Roswitha Wiltschko ${ }^{1, *}$ \\ 1 FB Biowissenschaften, Goethe-Universität Frankfurt am Main, Max-von-Laue-Str. 13, D-60438 Frankfurt am \\ Main, Germany; d.gehring@ect.de (D.G.); wiltschko@zoology.uni-frankfurt.de (W.W.) \\ 2 Abteilung Biopsychologie, Fakultät für Psychologie, Ruhr-Universität Bochum, D-44780 Bochum, Germany; \\ Onur.Guentuerkuen@rub.de \\ 3 Stellenbosch Institute for Advanced Study (STIAS), Wallenberg Research Centre at Stellenbosch University, \\ Stellenbosch 7600, South Africa \\ * Correspondence: wiltschko@bio.uni-frankfurt.de; Tel.: +49-69-798-24119
}

Academic Editor: Lesley J. Rogers

Received: 26 March 2017; Accepted: 12 May 2017; Published: 19 May 2017

\begin{abstract}
In European Robins, Erithacus rubecula, the magnetic compass is lateralized in favor of the right eye/left hemisphere of the brain. This lateralization develops during the first winter and initially shows a great plasticity. During the first spring migration, it can be temporarily removed by covering the right eye. In the present paper, we used the migratory orientation of robins to analyze the circumstances under which the lateralization can be undone. Already a period of $11 / 2 \mathrm{~h}$ being monocularly left-eyed before tests began proved sufficient to restore the ability to use the left eye for orientation, but this effect was rather short-lived, as lateralization recurred again within the next $11 / 2 \mathrm{~h}$. Interpretable magnetic information mediated by the left eye was necessary for removing the lateralization. In addition, monocularly, the left eye seeing robins could adjust to magnetic intensities outside the normal functional window, but this ability was not transferred to the "right-eye system". Our results make it clear that asymmetry of magnetic compass perception is amenable to short-term changes, depending on lateralized stimulation. This could mean that the left hemispheric dominance for the analysis of magnetic compass information depends on lateralized interhemispheric interactions that in young birds can swiftly be altered by environmental effects.
\end{abstract}

Keywords: avian magnetic compass; lateralization; right eye/left brain system; plasticity; commissures; Cryptochrome 1a

\section{Introduction}

In most vertebrates studied up to now, several perceptual, cognitive, and motor systems display a left-right difference of neural processing [1,2]. This ubiquity of functional brain asymmetries is probably the result of some fundamental benefits. Indeed, various studies could demonstrate in several species, ranging from fish to humans, that those individuals that are more strongly lateralized in a certain function also display higher performances when this function is tested [3-5]. This is possibly due to three mechanisms. First, asymmetries can selectively increase the perceptual or motor learning effect in one hemisphere. This is the case for, e.g., birds where the eyes are so laterally placed that most of the visual input derives from monocular vision. Thus, increased perceptual training of one eye can result in higher discrimination ability with this side [6]. The second mechanism for an advantage of asymmetry is directly related: increased learning with one perceptual or motor system also decreases reaction times, resulting in a time advantage of the dominant side $[7,8]$. The third mechanism of an advantage is parallel and complementary processing during task execution. If, for example, lateralized and non-lateralized chicks are tested in a foraging task that requires them to find grains scattered 
among pebbles and, at the same time, monitor overhead for a flying model predator, the strongly lateralized birds can conduct both tasks efficiently and in parallel [9]. Thus, hemispheric specialization seems to increase parallel processing by enabling separate processing of complementary information into the two hemispheres [10].

An important function that has been found to be lateralized is the avian magnetic compass. Information is obtained in the right eye and processed in the left hemisphere of the brain: with only their right eye open, birds could use their magnetic compass in the normal way, whereas they were disoriented when they had to use their left eye alone [11-15]. The reception of magnetic directional information is associated with the visual system. The Radical Pair Model, proposed by Ritz and colleagues [16], assumes that magnetoreception is based on spin-chemical processes in specialized photopigments; the eye was suggested as the site for magnetoreception, with cryptochromes as molecules forming the crucial radical pairs. Experimental evidence supports this model: radio-frequency fields in the MHz-range, a diagnostic tool for radical pair processes [17] disrupt magnetoreception (e.g., [18-22]). Furthermore, Cryptochrome 1a was found in the retina of birds, located along the disks of the outer segments of the UV/V cones [23], activated by light of the short wavelengths that allows birds magnetic compass orientation [24].

The first behavioral experiments documenting a lateralization of the magnetic compass in favor of the right eye/left hemisphere were performed with migratory birds, European Robins, Erithacus rubecula (Turdidae), and Australian Silvereyes, Zosterops l. lateralis, making use of their spontaneous directional preferences during the migratory phase [11,12]. Later studies, however, questioned these findings, reporting that migratory birds, among them European Robins, were oriented in their migratory direction even if they had to rely on their left eye alone [25-27]. Yet, there were marked differences between these studies, an important one being a difference in the test season: the tests documenting the lateralization of the magnetic compass had been spring experiments with birds returning to their breeding grounds whereas the tests not finding a lateralization were predominantly autumn experiments with birds mainly following an innate course (see [28]). A follow-up study testing the same robins consecutively during the first three migration seasons indicated that lateralization of the magnetic compass was not present in very young robins, but develops only after the first autumn migration [29]: initially, the magnetic compass was not lateralized and the birds could orient with their right as well as their left eye. During the following spring migration and the second autumn migration, in contrast, the same birds could no longer orient with their left eye alone-the magnetic compass had become lateralized in favor of the right eye/left brain hemisphere. Yet, in the beginning, the lateralization proved to be flexible with considerable plasticity: during spring migration, covering the right eye for $6 \mathrm{~h}$ prior to the orientation tests could temporarily restore the ability for magnetic compass orientation to the left eye. During the subsequent autumn migration, however, the same treatment no longer had any effect. These results strongly indicate that the magnetic compass asymmetry requires a developmental period: while it is absent during the first autumn and subsequently susceptible to change during the first spring, it becomes more strongly fixed beginning with the second autumn.

The flexible phase during spring migration is of particular interest because it allows some insights into the processes leading to the lateralization of the avian magnetic compass. Here, we report behavioral experiments during the first spring migration of migratory European Robins, designed to analyze in more detail the time-span required to restore magnetoreception to the left eye, the extent and the duration of this effect and the circumstances under which it takes place.

\section{Results}

The various test conditions are listed in Table 1. The results are summarized in Table 2, indicating significant differences between various treatments and the respective binocular controls; for the data of the individual birds, see Tables S1-S3a,b in the Supplementary Material. 


\subsection{The Effect of Monocular Pre-Exposure}

Our previous study [29] had shown that, during the first spring migration, covering the right eye for $6 \mathrm{~h}$ had temporarily restored the ability for magnetic compass orientation to the left eye. This raised the question of how this treatment affected the right eye. The respective data are given in Figure 1: after having the right eye covered for $6 \mathrm{~h}$, the robins could orient with their right eye (6hpeL-R) as well as with their left eye (6peL-L). Obviously, disrupting the input from the right eye for $6 \mathrm{~h}$ had no adverse effect on ability of the right eye/left hemisphere to process magnetic compass orientation; it just seems to remove the lateralization.

Table 1. Definition of the test conditions and their abbreviations.

\begin{tabular}{|c|c|}
\hline Abbreviation & Test Condition \\
\hline $\mathrm{Bi}$ & binocularly tested, control \\
\hline $\mathrm{L}$ & monocularly left-eyed \\
\hline 6peL-L & $6 \mathrm{~h}$ pre-exposed monocularly left-eyed, tested left-eyed \\
\hline 6peL-R & $6 \mathrm{~h}$ pre-exposed monocularly left-eyed, tested right-eyed \\
\hline 11/2peL-L & $11 / 2 \mathrm{~h}$ pre-exposed monocularly left-eyed, tested left-eyed \\
\hline $11 / 2 \mathrm{peL} / 11 / 2-\mathrm{L}$ & $11 / 2 \mathrm{~h}$ pre-exposed monocularly left-eyed, then $11 / 2 \mathrm{~h}$ without eye cover, tested left-eyed \\
\hline 3peRFBi-Bi & $3 \mathrm{~h}$ binocularly pre-exposed in an RF field (1.314 MHz, $480 \mathrm{nT})$, tested binocularly \\
\hline 3peRFL-L & $3 \mathrm{~h}$ monocularly left-eyed pre-exposed in a RF field $(1.314 \mathrm{MHz}, 480 \mathrm{nT})$, tested left-eyed \\
\hline 3pe92R-92R & $3 \mathrm{~h}$ right-eyed pre-exposed in a $92 \mu \mathrm{T}$ field, tested right-eyed in the $92 \mu \mathrm{T}$ field \\
\hline 3pe92L-92L & $3 \mathrm{~h}$ left-eyed pre-exposed in a $92 \mu \mathrm{T}$ field, tested left-eyed in the $92 \mu \mathrm{T}$ field \\
\hline 3pe92L-92R & $3 \mathrm{~h}$ left-eyed pre-exposed in a $92 \mu \mathrm{T}$ field, tested right-eyed in the $92 \mu \mathrm{T}$ field \\
\hline
\end{tabular}

If not indicated otherwise, the birds were pre-exposed and tested in the geomagnetic field. RF field: radio frequency field.

Table 2. Orientation after various lengths and modes of monocular pre-exposure. Twelve birds were tested in all test conditions (48 birds altogether, see Tables in Supplementary Material).

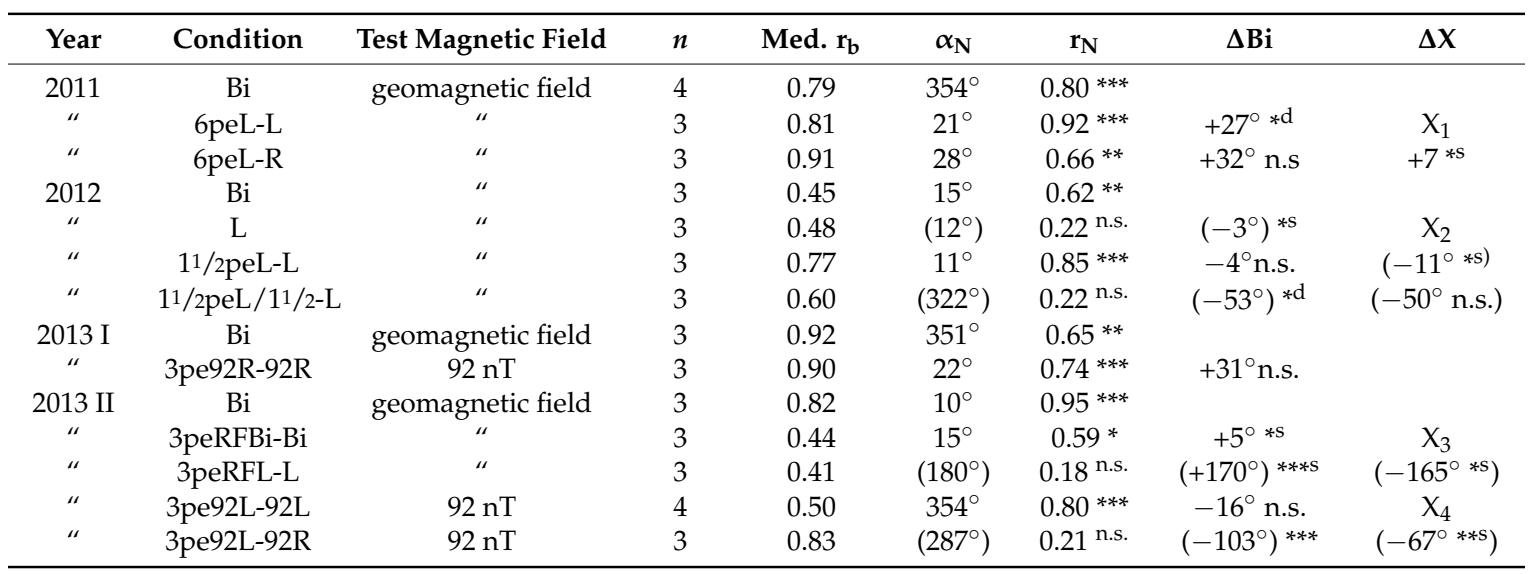

For the definition of the test conditions, see Table 1. $n$, tests per bird; med-r $\mathrm{r}_{\mathrm{b}}$, median vector length per birds; $\alpha_{\mathrm{N}}$, $\mathrm{r}_{\mathrm{N}}$, direction and length of grand mean vector, with asterisks indicating significant directional preference by the Rayleigh test [30] ( $\alpha_{\mathrm{N}}$ in parentheses if not significant). $\Delta \mathrm{Bi}$, difference to the respective binocular control, and $\Delta \mathrm{X}$, difference to the $\mathrm{X}$-sample above, with asterisk indication a significance of the difference by the Mardia Watson Wheeler test (d) and the Mann-Whitney U-test (s). ${ }^{* * *} p<0.001 ;{ }^{* *} p<0.01 ;{ }^{*} p<0.05 ;$ n.s.: not significant. 

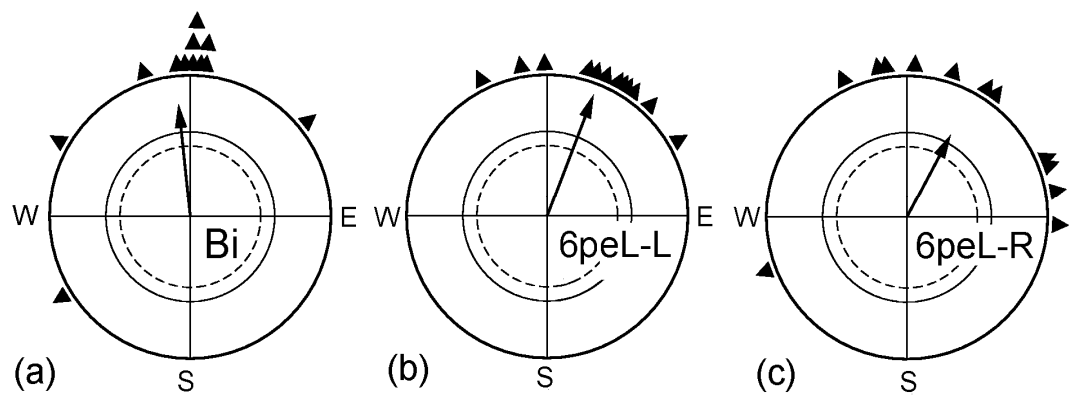

Figure 1. Effect of covering the right eye for $6 \mathrm{~h}$ prior to the test. (a) Untreated binocular control; (b) Birds tested monocularly left-eyed after having the right eye covered for $6 \mathrm{~h}$; (c) Birds tested monocularly right-eyed after having the right eye covered for $6 \mathrm{~h}$. The triangles at the periphery of the circle indicate the mean headings of the individual birds; the arrow represents the grand mean vector in relation to the radius of the circle $=1$, and the inner circles mark the $5 \%$ (dotted) and the $1 \%$ significance border of the Rayleigh test [30].

Another question concerned the duration of the interval required to restore the ability to use information from the left eye and how long the effect would last. The data are given in Figure 2. When the right eye was covered immediately before the test (L), the monocularly left-eyed birds were disoriented, documenting lateralization in favor of the right eye. If the birds had been monocularly left-eyed already $11 / 2 \mathrm{~h}$ before the tests began (11/2peL-L), they showed normal orientation with their left eye, not different from when they were tested as binocular controls (Bi). However, this effect of removing the lateralization proved to be rather short-lived: when the birds had been monocularly left-eyed for $11 / 2 \mathrm{~h}$, followed by a binocular period of another $11 / 2 \mathrm{~h}$ and were then tested left-eyed immediately afterwards (11/2peL/11/2-L), they were disoriented (Figure $2 \mathrm{~d}$ ) -lateralization had set in again.
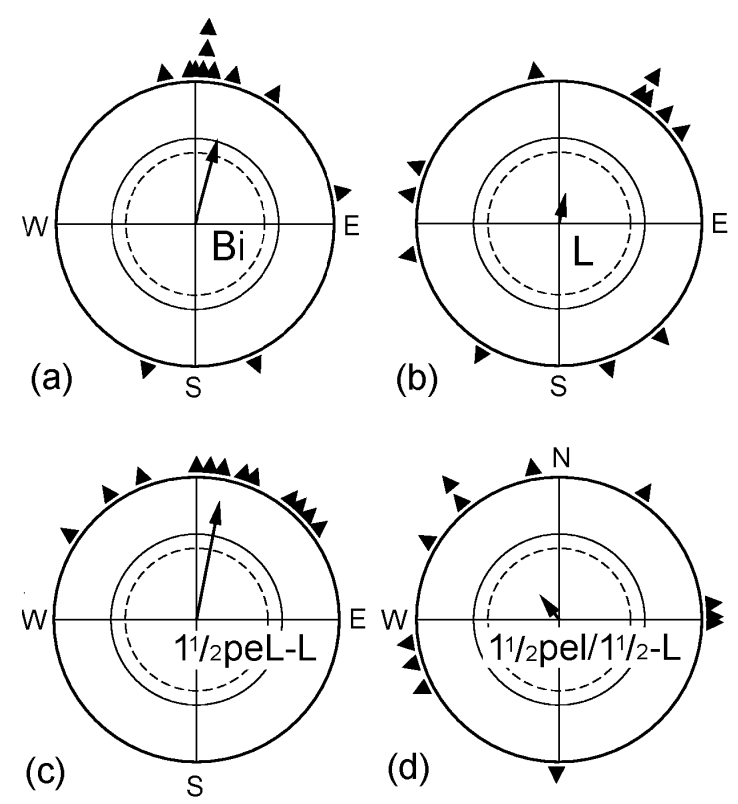

Figure 2. Time required for removing the lateralization in favor of the right eye. (a) Untreated binocular control; (b) Birds tested monocularly left eyed; their right eye was covered immediately before the tests began, indicating the lateralization in favor of the right eye; (c) Birds tested monocularly left eyed after having the right eye covered $11 / 2 \mathrm{~h}$ before the beginning of the tests; (d) Birds tested monocularly left eyed after having the right eye covered for $11 / 2 h$, and then the cover was removed for $11 / 2 h$ before the beginning of the tests. Symbols as in Figure 1. 


\subsection{Pre-Exposure in Altered Magnetic Conditions}

The previously described tests showing a temporary removal of lateralization as an effect of covering the right eye had been performed in the local geomagnetic field. With the following treatments, we tested for possible effects of the magnetic conditions during monocular deprivation.

First, we pre-exposed birds binocularly to a radio-frequency field that had been shown to disrupt magnetic orientation [19]. This meant that the birds did not receive interpretable magnetic information during a period $3 \mathrm{~h}$ immediately before the tests began (3peRFBi-Bi). Immediately after the pre-exposure, these birds were significantly oriented in their migratory direction in the geomagnetic field (see Figure $3 b$ ), even if the distribution of their mean headings shows a certain increase in scatter. Birds that were exposed monocularly left-eyed to the radio frequency field for $3 \mathrm{~h}$ immediately before they were tested left-eyed (3peRFL-L), in contrast, were disoriented in the geomagnetic field immediately afterwards (Figure 3c). Covering the right eye for a period of $3 \mathrm{~h}$, twice as long as the one used in the previous series, should have been sufficient to enable the birds to use their left eye for obtaining magnetic compass orientation, yet in this case, it did not work. Obviously, receiving only visual information from the left eye could not remove the lateralization. Our data clearly show that interpretable directional information from the magnetic field is essential for allowing the processing of magnetic information by the left eye again.

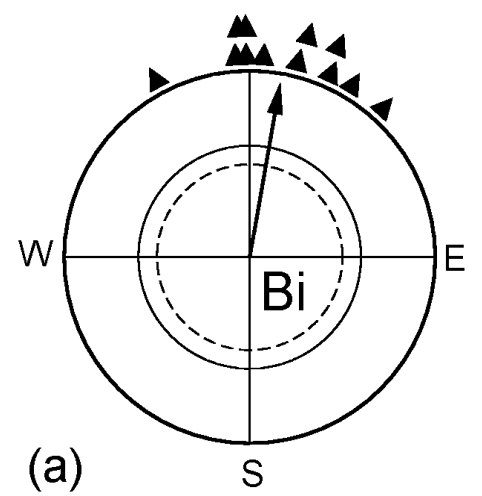

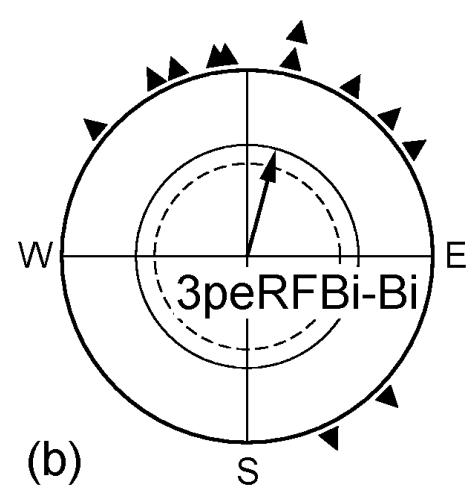

(c)

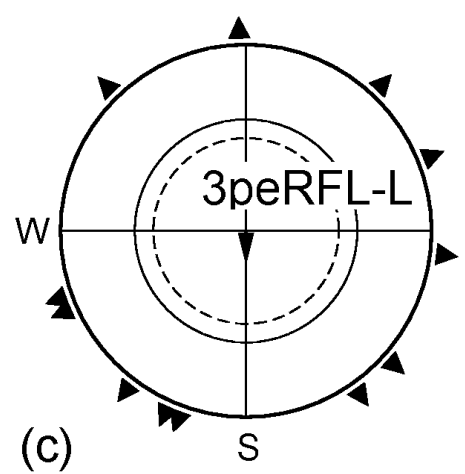
Figure 3. Effect of denying the birds interpretable magnetic information before the tests. (a) Untreated
binocular control; (b) Birds exposed binocularly to a radio frequency for $3 \mathrm{~h}$ prior to being tested binocularly in the local geomagnetic field; (c) Birds exposed monocularly left-eyed to the radio frequency field for $3 \mathrm{~h}$ prior to being tested monocularly left-eyed in the geomagnetic field. Symbols as in Figure 1.

In a next step, we exposed the birds prior to the tests for $3 \mathrm{~h}$ to a magnetic field of $92 \mu \mathrm{T}$, twice as strong as the local geomagnetic field. Robins cannot spontaneously cope with such field strengths, but become able to orient in it if they had a chance to adjust to this intensity before the tests. In a previous study, $1 \mathrm{~h}$ pre-exposure to such a strong field had proven sufficient to allow orientation [31]. We tested two different groups of birds: Group I was pre-exposed with the right eye open and subsequently tested monocularly right-eyed (3pe92R-92R). Group II was pre-exposed and tested monocularly left-eyed (3pe92L-92L). The results are given in Figure 4: both groups of birds were oriented in the strong magnetic field. However, there was a difference between the groups: while the right-eyed birds were oriented in their migratory direction right away, with the headings of the three tests not different from each other, the left eyed birds were first disoriented and oriented only from the third test onward, with only the distribution of the forth headings significantly different from the disoriented first round (see Table 3). When left-eyed, the birds thus required more time to adjust to the stronger field. 

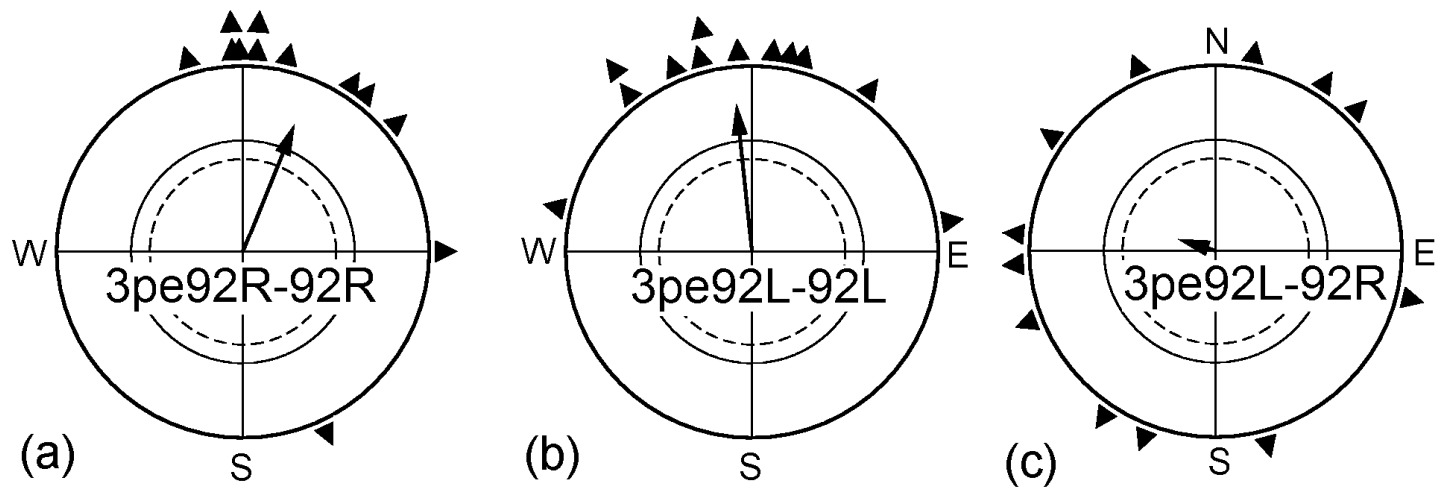

Figure 4. Adjusting to higher magnetic intensities. (a) Birds of group I pre-exposed monocularly right-eyed for $3 \mathrm{~h}$ in a magnetic field of $92 \mu \mathrm{T}$, twice the intensity of the geomagnetic field, and then were tested in that field; (b) Birds of group II pre-exposed monocularly left-eyed for $3 \mathrm{~h}$ in the strong magnetic field then tested in that field; (c) Birds of group II pre-exposed monocularly left-eyed for $3 \mathrm{~h}$ in the strong magnetic field and then tested monocularly right-eyed in that field. For the orientation of the untreated control birds, see Figure 3a and Table 2. Symbols as in Figure 1.

Table 3. Orientation of the robins pre-exposed and tested in the $92 \mu \mathrm{T}$-field.

\begin{tabular}{ccccccccc}
\hline \multirow{2}{*}{$\begin{array}{c}\text { Test } \\
\text { Round }\end{array}$} & \multicolumn{3}{c}{ Monocularly Right-Eyed Birds } & \multicolumn{4}{c}{ Monocularly Left-Eyed Birds } \\
\cline { 2 - 9 } & $\boldsymbol{N}$ & $\boldsymbol{\alpha}$ & $\mathbf{r}$ & $\boldsymbol{\Delta}_{\text {Round 1 }}$ & $\boldsymbol{N}$ & $\boldsymbol{\alpha}$ & $\mathbf{r}$ & $\boldsymbol{\Delta}_{\text {Round 1 }}$ \\
\hline 1 & 12 & $8^{\circ}$ & $0.87^{* * *}$ & & 11 & $\left(304^{\circ}\right)$ & $0.38^{\text {n.s }}$ & \\
2 & 11 & $\left(20^{\circ}\right)$ & $0.46^{\text {n.s }}$ & $+12^{\circ}$ n.s. & 12 & $\left(10^{\circ}\right)$ & $0.36^{\text {n.s. }}$ & $+66^{\circ}$ n.s. \\
3 & 10 & $22^{\circ}$ & $0.64^{* *}$ & $+14^{\circ}$ n.s. & 11 & $3^{\circ}$ & $0.54^{*}$ & $+59^{\circ}$ n.s. \\
4 & & & & & 12 & $13^{\circ}$ & $0.74^{* * *}$ & $+69^{\circ} *$ \\
\hline
\end{tabular}

$N$, number of birds contributing; $\alpha, r$, direction and length of mean vector, with asterisks at $r$ indicating a significant directional preference by the Rayleigh Test [30] (Batschelet, 1981). The column $\Delta_{\text {Round } 1}$ gives differences to the behavior in the first test round, with asterisks indicating significance; symbols as in Table 2.

Birds that had been pre-exposed monocularly left-eyed to the $92 \mu \mathrm{T}$ field for $3 \mathrm{~h}$ were tested monocularly right-eyed in the same $92 \mu \mathrm{T}$ field; however, they were disoriented (Figure 4c). While covering the left eye per se did not interfere with the ability of the right eye to mediate magnetic directional information (see Figure 1c), the right eye/left hemisphere could not cope with the increased intensity if it had not experienced the respective magnetic condition before. For adjusting to higher field strengths, processing of such input in the respective hemisphere seems to be required-there appears to be no transfer from the right to the left hemisphere where the adjustment to higher magnetic intensities is concerned.

\section{Discussion}

Our data show that, during the first spring migration, the lateralization of the magnetic compass in favor of the right eye/left hemisphere of the brain can be easily undone by covering the right eye for a short time. However, this activation of the left eye/right hemisphere system does, in turn, not seem to affect the right eye. Interpretable magnetic information mediated by the left eye is essentially required to remove the lateralization. When the left eye system is activated, it can adjust to intensities outside the functional window of the magnetic compass (see [32]), but if it does, this ability is not transferred to the right eye system.

The directional information from the magnetic field originates in the retina and is transmitted by the visual nerve to higher centers in the brain (e.g., [33-35]). There are two main ascending visual systems in the bird brain that reach the telencephalon: one is the tectofugal system that runs from the retina via the optic tectum to the thalamic nucleus rotundus, which, in turn, projects to the 
entopallium. The second is the thalamofugal system that ascends from the retina via a thalamic link to a telencephalic area called wulst [36]. Anatomical and physiological studies in pigeons could demonstrate that both systems display asymmetries with a dominance of the left hemisphere. The tectofugal system is characterized by diverse anatomical and physiological asymmetries along its route [37-41]. Consequently, left-sided tectofugal lesions result in more severe visual deficits than right-sided ones [42,43]. In the thalamofugal system, the left- but not the right-sided wulst is able to importantly modify activity patterns of the tectofugal pathway [44]. Thus, both ascending visual pathways are lateralized with a superiority of the right eye and constitute a leading role of the left hemisphere, e.g., in recognizing and categorizing objects $[45,46]$. This could also be the reason for the normal dominance of the right eye/left hemisphere system in magnetoreception. At the same time, several commissural fibers that run through the tectal and posterior commissures are asymmetrically organized in birds such that the left tectum is less inhibited by its right counterpart than vice versa [47]. As a consequence, the dominant left hemisphere is able to inhibit the subdominant right. Inhibitory interactions are possibly crucial when only one function for which one hemisphere is dominant has to be executed [48]. Against this background, we will discuss our findings.

\subsection{Fast Re-Activation of the Left Eye/Right Hemisphere System for Sensing Magnetic Directions}

A mere $11 / 2 \mathrm{~h}$ of covering the right eye enabled the robins to orient with their left eye. This extends the findings of our previous study [29] and shows that the lateralization of magnetic compass orientation is still amenable to changes during the first spring migration. Ninety minutes is probably too short for major anatomical changes within the visual pathway [49]. It is more likely that the causal mechanisms for re-activation of the left eye system are related to the short-term synaptic plasticity of the strength of commissural synapses. As the dominant left hemisphere is able to inhibit the subdominant right [47,48], the functional asymmetry of the magnetic compass could be constituted via asymmetrically organized inhibitory interactions between the two hemispheres. Both the left and the right hemispheres are obviously able to do the task during the first spring migration, but, under normal conditions, the dominant left hemisphere (right eye) would inhibit the subdominant right half brain (left eye). This asymmetrical inhibition is abolished after forcing the animal to use the left eye alone for $11 / 2 \mathrm{~h}$. However, these birds return to their left hemispheric dominance after just another further $11 / 2 \mathrm{~h}$ of binocular vision. Thus, left hemisphere (right eye) dominance seems to be the normal state of the magnetic compass system. In young birds, this condition is subject to plasticity after the accumulation of left eye experience, but it returns to its previous status once the right eye can be used again.

The short time of $11 / 2 \mathrm{~h}$ required to enable birds to use their left eye during spring migration could also explain some of the seemingly controversial findings in the literature. Engels and colleagues [27] reported that they did not find lateralization of the magnetic compass in their spring experiments with robins. In their method section, the authors quote previous studies $[25,50]$ that imply that the covering of the right eye occurred at least $2 \mathrm{~h}$ before the tests began, often earlier-this would have allowed sufficient time for the neural circuit to process information from the left eye again.

\subsection{Conditions Required for the Re-Activation of the Left Eye/Right Hemisphere System}

The findings of the second part of our study are more difficult to interpret because they touch the still open question of whether the reception of magnetic directions is an integrated part of vision or magnetic information is processed more or less independently as a sense of its own.

Learning visual discrimination tasks takes longer with the left eye/right hemisphere than with the right eye, and in several cases of bilateral learning, the right hemisphere did not share the knowledge, but had to be trained separately (e.g., [51,52]; for review, see [53]). It is unclear whether the longer time required for the left eye/right hemisphere system to adjust to higher magnetic intensities represents a parallel case. We exposed the robins prior to the tests for $3 \mathrm{~h}$ to a higher magnetic field of $92 \mu \mathrm{T}$. As shown previously [31], robins need about $1 \mathrm{~h}$ to orient in this field strength. Robins allowed to 
use their right eye were oriented right away, but this was not so for the left-eyed birds; they took considerably longer. This appears to be in accordance with the results of discrimination studies mentioned above. The adjustment to higher magnetic intensities means that the birds become able to interpret a slightly different activation pattern on the retina (see [16,31]); it can start only after the ability to process magnetic information has been restored to left eye/right hemispheres. However, this alone can probably not account for the longer delay of the left eye system, as our experiments show that it requires only $11 / 2 \mathrm{~h}$, possibly less. It means that the left eye system is indeed considerably slower in performing the adjustment, requiring much longer than the $1 \mathrm{~h}$ observed in binocular birds [31].

Once the left eye system could orient in the stronger magnetic field of $92 \mu \mathrm{T}$, this ability was not directly transferred to the right eye system. This is contrary to the results of most visual discriminations tasks, which found a more efficient transfer of visual discrimination from the left eye to the right eye $[43,51,52]$. This is assumed to be due to the more bilateral left hemispheric visual representation in the tectofugal pathway that enables the right eye system to swiftly access left eye information [38]. The fact that our result pattern runs contrary to these data from visual pattern discrimination studies indicates that magnetic compass information is processed differently from visual patterns. It could also be related to the thalamofugal wulst system where cluster $N$ was suggested to be a central hub of magnetic compass processing ([35], but see [54]). At least in pigeons, the wulst is known to modify lateralized activity patterns of the tectofugal pathway $[41,44]$ and to thereby affect interhemispheric exchange of information [43].

An important finding in the experiments with left-eyed birds is that exposure to a radio-frequency field that disrupts magnetic orientation $[18,19]$ did not result in an ability to orient with the left eye, although this eye had had access to visual information. Obviously, the change in asymmetry concerning magnetic compass information is not the result of mere right-eye monocular occlusion. What is required for this kind of change is the ability to sense interpretable magnetic compass information with the left eye during periods of absence of right eye input - if this specific requirement is not met, the normal left hemispheric (right eye) dominance prevails. This, too, seems to indicate that magnetic directional information is processed differently from visual input, with the specific magnetic stimulus necessary to overcome the normal lateralization in favor of the right eye system. However, it is also conceivable that magnetic compass information is just a specific kind of visual input within the visual system and that disruption of this input through a radio-frequency field makes it impossible for the left eye/right hemisphere system to regain the ability to process this specific input class. Details of how magnetic compass information is processed have to be analyzed in further studies.

\subsection{Lasting Flexibility in the Avian Magnetic Compass?}

Our results clearly show that, during the first spring migration, both hemispheres are in principle able to process magnetic compass information. Indeed, in a histological study [23], Cryla, the putative receptor molecule, was found in both eyes alike in robins almost a year old, i.e., after spring migration was finished. Older robins were not examined, but at least in Domestic Chickens, Gallus gallus, Cryla was still present in both eyes when they are more than two years old [55]. This suggests that magnetic directional information could still be provided by the left eye and processed in the right hemisphere, but that it is actively suppressed by the left hemisphere-information from the left eye is no longer processed as long as corresponding information from the right eye is transmitted to the brain. However, if this is interrupted, it can be replaced by that from the left eye. The observation that the right eye system is not affected by being temporarily covered and that the re-gained ability to use the information from the left eye is lost rather quickly when the right eye is open again demonstrates the dominance of the right eye/left hemisphere in processing magnetic directional information.

For this study, we used young robins during their first spring migration, i.e., birds less than one year old; older birds roughly 11/2 years old had proven less flexible in an earlier study [29]. It seems possible that changes of asymmetry are easier during early ontogeny and less flexible in adult individuals. Indeed, Lesley Rogers [46,56] pioneered studies on the ontogenetic establishment of visual 
asymmetries in chicks and could demonstrate that both functional and anatomical lateralized systems can be easily modified in early ontogeny, with a similar effect also observed in young pigeons $[57,58]$. In Japanese quails, a life-long potential for plasticity has been observed [7]. Hence, we cannot exclude that in robins and other birds the left eye/right hemisphere system can still be activated in later years, but this appears to require more time than the six hours for which we tested during the second autumn migration [29]. Possibly, if a bird is injured and loses its right eye, its brain proves flexible enough to eventually restore magnetoreception to the left eye system. Studies in humans make it likely that asymmetries that depend on lateralized commissural interactions can retain their plasticity up to late adulthood [59].

\section{Material and Methods}

The experiments were performed during spring migration of the years 2011 to 2013 in the garden of the Zoological Institute of the University of Frankfurt am Main $\left(50^{\circ} 08^{\prime} \mathrm{N}, 8^{\circ} 40^{\prime} \mathrm{E}\right)$.

\subsection{Experimental Birds}

The test birds were European Robins, a passerine species that is distributed all over Europe. The northern populations are nocturnal migrants and spend the winter in the Mediterranean region. In September, juvenile birds were caught using mist nets in the Botanical Garden of Frankfurt am Main, right next to the test sites and were identified as transmigrants of Scandinavian origin by their wing lengths. They were housed in individual cages in a photoperiod simulating the natural one until early December, when it was decreased to L:D 8:16. Around New Year, it was increased in two steps to L:D 13:11. This induced premature migratory activity and allowed us to conduct spring experiments already in January and February. After the end of the experiments, the birds were released in the Botanical Garden in the beginning of April when the photoperiod outside had reached $13 \mathrm{~h}$.

\subsection{Covering One Eye}

With all experimental test series, we ran control tests with the same individual birds, testing them binocularly (Bi) without any treatment, because previous tests proved any unspecific effects from covering one eye to be negligible. The methods used to cover one eye for monocular testing was identical with those used in earlier studies with migratory birds [11,12,29]: a small non-magnetic aluminum cap was placed over the eye to be covered, fixed with adhesive tape (Leukoplast), as shown in Figure 1 in [11]. This was done either immediately before the tests started or at predetermined intervals before tests began; in some treatments, the eye-cover was removed before tests started and the other eye was covered instead. The various test conditions are defined in Table 1. Immediately after each test, any eye cover was removed and the birds were returned to their housing cages.

\subsection{Test Performance}

Testing followed our standard procedure, see, e.g., [11,18,29]: the test sites were wooden houses in the garden of the Zoological Institute where the geomagnetic field ( $46 \mu \mathrm{T}, 66^{\circ}$ inclination) was largely undisturbed. The birds were tested individually once per day in funnel-shaped cages lined with thermo-paper [60] where they left scratches as they moved. The cage was lit with green light, our standard control light. Each test lasted about $1 \mathrm{~h}$. The individual birds were mostly tested three times in each test condition, in one condition four times (see Table 2).

In two test conditions, the birds were exposed to a radio-frequency field of $1.315 \mathrm{MHz}$ (the local Larmor frequency) and $480 \mathrm{nT}$ for $3 \mathrm{~h}$ before they were tested. This field was produced by a coil antenna consisting of a single winding of coaxial cable with $2 \mathrm{~cm}$ of the screening removed. This antenna was mounted horizontally on a wooden frame and was fed by oscillating currents from a high frequency generator, generating the oscillating field vertically, i.e., at a $24^{\circ}$ angle to the vector of the geomagnetic field (for details, see $[18,19,61]$ ); four birds at a time were exposed in this field in all-plastic housing cages. In another test series, the birds were pre-exposed to, and tested in a magnetic field of $92 \mu \mathrm{T}$, 
twice the strength of the local geomagnetic field. This field was produced by Helmholtz coils ( $2 \mathrm{~m}$ in diameter and $1 \mathrm{~m}$ clearance) arranged in the way that the induced field added to the geomagnetic field, increasing the intensity, but not altering magnetic North and inclination [31].

\subsection{Data Analysis and Statistics}

After each test, the thermo-paper was removed from the funnels, virtually divided into 24 uniform sectors, and the scratches in these 24 sectors were counted by a person blind to the test conditions. Tests with less than a total of 35 scratches were considered to be of too little activity and were discarded; these tests were repeated with the same bird at the end of the test period. From the distribution of the scratches, the heading of the bird in the respective test was determined. The headings of each bird in each test condition were added to calculate a vector with the heading $\alpha_{b}$ and the length $r_{b}$. From these headings $\alpha_{\mathrm{b}}$, we calculated second order grand mean vectors for the various test conditions, which were tested for significant directional preference using the Rayleigh test [30]. The data of monocular treatments were compared with the binocular control data and the data from the same birds in different treatments with the Mardia Watson Wheeler test for differences in distribution, and the Mann-Whitney $\mathrm{U}$ test was applied to the differences of the birds' mean bearings from the grand mean for differences in variance [30]. From the individual vector lengths $\mathrm{r}_{\mathrm{b}}$, medians were calculated for each test condition; they reflect the intra-individual variance.

Supplementary Materials: The following are available online at www.mdpi.com/2073-8994/9/5/77/s1, Table S1: Data Spring 2011, Table S2: Data Spring 2012, Table S3: Data Spring 2013.

Acknowledgments: O.G. was supported by the Deutsche Forschungsgemeinschaft through Sonderforschungbereich 874; R.W was supported by the Deutsche Forschungsgemeinschaft through the grant Wi 988/8-2. We thank the students of the advanced lab classes, E. Berger, E. Dylda, D. Kringel, M. Kubi, P. Slattery and M. Wellmann, who helped us in carrying out the experiments.

Author Contributions: D.G., O.G., W.W. and R.W. conceived and designed the experiments; D.G., R.W. and W.W. performed the experiments; D.G. analyzed the data; R.W. and O.G. wrote the paper, with O.G. contributing substantially to the discussion.

Conflicts of Interest: The authors declare no conflict of interest.

Ethical Statement: The experiments were performed according to the rules and regulations for Animal Welfare in Germany, under the permit V54-19c20/15-F104/54 issued by the Regierungspräsidium Darmstadt (regional council) of the State of Hessen on 22.12.2010, extended on the 12.9.2012 until 31.12.2013.

\section{References}

1. Ocklenburg, S.; Ströckens, F.; Güntürkün, O. Lateralisation of conspecific vocalisation in non-human vertebrates. Laterality 2013, 18, 1-31. [CrossRef]

2. Ströckens, F.; Güntürkün, O.; Ocklenburg, S. Limb preferences in non-human vertebrates. Laterality 2013, 18, 536-575. [CrossRef]

3. Güntürkün, O.; Diekamp, B.; Manns, M.; Nottelmann, F.; Prior, H.; Schwarz, A.; Skiba, M. Asymmetry pays: Visual lateralization improves discrimination success in pigeons. Curr. Biol. 2000, 10, 1079-1081. [CrossRef]

4. Dadda, M.; Bisazza, A. Does brain asymmetry allow efficient performance of simultaneous tasks? Anim. Behav. 2006, 72, 523-529. [CrossRef]

5. Hirnstein, M.; Hugdahl, K.; Hausmann, M. How brain asymmetry relates to performance-A large-scale dichotic listening study. Front. Psychol. 2014, 4, 997. [CrossRef]

6. Ventolini, N.; Ferrero, E.A.; Sponza, S.; Della Chiesa, A.; Zucca, P.; Vallortigara, G. Laterality in the wild: Preferential hemifield use during predatory and sexual behaviour in the black-winged stilt. Anim. Behav. 2005, 69, 1077-1084. [CrossRef]

7. Gülbetekin, E.; Güntürkün, O.; Dural, S.; Cetinkaya, H. Visual asymmetries in Japanese quail (Coturnix japonica) retain a lifelong potential for plasticity. Behav. Neurosci. 2009, 123, 815-821. [CrossRef] [PubMed]

8. Vallortigara, G.; Chiandetti, C.; Sovrano, V.A. Brain asymmetry (animal). WIREs Cogn. Sci. 2011, 2, $146-157$. [CrossRef] [PubMed] 
9. Rogers, L.J.; Zucca, P.; Vallortigara, G. Advantages of having a lateralized brain. Proc. R. Soc. B 2004, 271 (Suppl. S6), S420-S422. [CrossRef] [PubMed]

10. Vallortigara, G. The evolutionary psychology of left and right: Costs and benefits of lateralization. Dev. Psychobiol. 2006, 48, 418-427. [CrossRef] [PubMed]

11. Wiltschko, W.; Traudt, J.; Güntürkün, O.; Prior, H.; Wiltschko, R. Lateralisation of magnetic compass orientation in a migratory bird. Nature 2002, 419, 467-470. [CrossRef]

12. Wiltschko, W.; Munro, U.; Ford, H.; Wiltschko, R. Lateralisation of magnetic compass orientation in Silvereyes, Zosterops lateralis. Aust. J. Zool. 2003, 51, 597-602. [CrossRef]

13. Rogers, L.; Munro, U.; Freire, R.; Wiltschko, R.; Wiltschko, W. Lateralized response of chicks to magnetic cues. Behav. Brain Res. 2008, 186, 66-71. [CrossRef] [PubMed]

14. Stapput, K.; Güntürkün, O.; Hoffmann, K.P.; Wiltschko, R.; Wiltschko, W. Magnetoreception of directional information requires non-degraded vision. Curr. Biol. 2010, 20, 1259-1262. [CrossRef] [PubMed]

15. Wilzeck, C.; Wiltschko, W.; Güntürkün, O.; Wiltschko, R.; Prior, H. Lateralization of magnetic compass orientation in pigeons. J. R. Soc. Interface 2010, 7, 235-240. [CrossRef] [PubMed]

16. Ritz, T.; Adem, S.; Schulten, K. A model for photoreceptor-based magnetoreception in birds. Biophys. J. 2000, 78, 707-718. [CrossRef]

17. Henbest, K.B.; Kukura, P.; Rodgers, C.T.; Hore, P.J.; Timmel, C.R. Radio frequency magnetic field effects on a radical recombination reaction: A diagnostic test for the radical pair mechanism. J. Am. Chem. Soc. 2004, 126, 8102-8103. [CrossRef] [PubMed]

18. Ritz, T.; Thalau, P.; Philllips, J.B.; Wiltschko, R.; Wiltschko, W. Resonance effects indicate a radical-pair mechanism for avian magnetic compass. Nature 2004, 429, 177-180. [CrossRef] [PubMed]

19. Thalau, P.; Ritz, T.; Stapput, K.; Wiltschko, R.; Wiltschko, W. Magnetic compass orientation of migratory birds in the presence of a 1.315 MHz oscillating field. Naturwissenschaften 2005, 92, 86-90. [CrossRef] [PubMed]

20. Wiltschko, W.; Freire, R.; Munro, U.; Ritz, T.; Rogers, L.; Thalau, P.; Wiltschko, R. The magnetic compass of domestic chickens, Gallus gallus. J. Exp. Biol. 2007, 210, 2300-2310. [CrossRef] [PubMed]

21. Keary, N.; Roploh, T.; Voss, J.; Thalau, P.; Wiltschko, R.; Wiltschko, W.; Bischof, H.J. Oscillating magnetic field disrupts magnetic orientation in Zebra finches, Taeniopygia guttata. Front. Zool. 2009, 6, 25. [CrossRef] [PubMed]

22. Kavokin, K.; Chernetsov, N.; Pakomov, A.; Bojarinova, J.; Kobylkov, D.; Namozov, B. Magnetic orientation of garden warblers (Sylvia borin) under 1.4 MHz radio frequency field. J. R. Soc. Interface 2014, 11, 20140451. [CrossRef] [PubMed]

23. Nießner, C.; Denzau, S.; Gross, J.C.; Peichl, L.; Bischof, H.J.; Fleissner, G.; Wiltschko, W.; Wiltschko, R. Avian ultraviolet/violet cones identified as probable magnetoreceptors. PLoS ONE 2011, 6, e20091. [CrossRef] [PubMed]

24. Nießner, C.; Denzau, S.; Stapput, K.; Ahmad, M.; Peichl, L.; Wiltschko, W.; Wiltschko, R. Magnetoreception: Activated cryptochrome 1a concurs with magnetic orientation in birds. J. R. Soc. Interface 2013, 10, 20130618.

25. Hein, C.M.; Zapka, M.; Heyers, D.; Kurzschbauch, S.; Schneider, N.-L.; Mouritsen, H. Night-migratory Garden Warblers can orient with their magnetic compass using the left, the right or both eyes. J. $R$. Soc. Interface 2010, 7, S227-S233. [CrossRef] [PubMed]

26. Hein, C.M.; Engels, S.; Kishkinev, D.; Mouritsen, H. Robins have a magnetic compass in both eye. Nature 2011, 271, E11-E12. [CrossRef] [PubMed]

27. Engels, S.; Hein, C.; Lefeldt, N.; Prior, H.; Mouritsen, H. Night-migratory songbirds possess a magnetic compass in both eye. PLOS ONE 2012, 7, e43271. [CrossRef] [PubMed]

28. Wiltschko, W.; Traudt, J.; Güntürkün, O.; Prior, H.; Wiltschko, R. Reply to Hein et al. Nature 2011, 471, E12-E13.

29. Gehring, D.; Wiltschko, W.; Güntürkün, O.; Denzau, S.; Wiltschko, R. Development of lateralization of the magnetic compass in a migratory bird. Proc. R. Soc. B 2012, 279, 4230-4235. [CrossRef] [PubMed]

30. Batschelet, E. Circular Statistics in Biology; Academic Press: London, UK, 1981.

31. Wiltschko, W.; Stapput, K.; Thalau, P.; Wiltschko, R. Avian magnetic compass: Fast adjustment to intensities outside the normal functional window. Naturwissenschaften 2006, 93, 300-304. [CrossRef] [PubMed]

32. Wiltschko, R.; Wiltschko, W. Sensing magnetic directions in birds: Radical pair processes involving cryptochrome. Biosensors 2014, 4, 221-242. [CrossRef] [PubMed] 
33. Semm, P.; Demaine, C. Neurophysiological properties of magnetic cells in the pigeon's visual system. J. Comp. Physiol. A 1986, 159, 619-625. [CrossRef] [PubMed]

34. Heyers, D.; Manns, M.; Luksch, H.; Güntürkün, O.; Mouritsen, H. A visual pathway links brain structures active during magnetic compass orientation in migratory birds. PLoS ONE 2007, 9, e937. [CrossRef] [PubMed]

35. Zapka, M.; Heyers, D.; Hein, C.M.; Engels, S.; Schneider, N.L.; Hans, J.; Weiler, S.; Dreyer, D.; Kishkinev, D.; Wild, J.M.; et al. Visual but not trigeminal mediation of magnetic compass information in a migratory bird. Nature 2009, 461, 1274-1277. [CrossRef] [PubMed]

36. Mouritsen, H.; Heyers, D.; Güntürkün, O. The neural basis of long-distance navigation in birds. Annu. Rev. Physiol. 2016, 78, 133-154. [CrossRef] [PubMed]

37. Güntürkün, O. Morphological asymmetries of the tectum opticum in the pigeon. Exp. Brain Res. 1997, 116, 561-566. [CrossRef] [PubMed]

38. Güntürkün, O.; Hellmann, B.; Melsbach, G.; Prior, H. Asymmetries of representation in the visual system of pigeons. Neuroreport 1998, 9, 4127-4130. [CrossRef] [PubMed]

39. Ströckens, F.; Freund, N.; Manns, M.; Ocklenburg, S.; Güntürkün, O. Visual asymmetries and the ascending thalamofugal pathway in pigeons. Brain Struct. Funct. 2013, 218, 1197-1209. [CrossRef] [PubMed]

40. Manns, M.; Güntürkün, O. "Natural" and artificial monocular deprivation effects on thalamic soma sizes in pigeons. Neuroreport 1999, 10, 3223-3228. [CrossRef] [PubMed]

41. Folta, K.; Diekamp, B.; Güntürkün, O. Asymmetrical modes of visual bottom-up and top-down integration in the thalamic nucleus rotundus of pigeons. J. Neurosci. 2004, 24, 9475-9485. [CrossRef] [PubMed]

42. Güntürkün, O.; Hahmann, U. Visual acuity and hemispheric asymmetries in pigeons. Behav. Brain Res. 1994, 60, 171-175. [CrossRef]

43. Valencia-Alfonso, C.-E.; Verhaal, J.; Güntürkün, O. Ascending and descending mechanisms of visual lateralization in pigeons. Philos. Trans. Roy. Soc. B 2009, 364, 955-963. [CrossRef] [PubMed]

44. Freund, N.; Valencia-Alfonso, C.E.; Kirsch, J.; Brodmann, K.; Manns, M.; Güntürkün, O. Asymmetric top-down modulation of ascending visual pathways in pigeons. Neuropsychologia 2016, 83, 37-47. [CrossRef] [PubMed]

45. Yamazaki, Y.; Aust, U.; Huber, L.; Hausmann, M.; Güntürkün, O. Lateralized cognition: Asymmetrical and complementary strategies of pigeons during discrimination of the "human concept". Cognition 2007, 104, 315-344. [CrossRef] [PubMed]

46. Rogers, L.J. Asymmetry of brain and behavior in animals: Its development, function, and human relevance. Genesis 2014, 52, 555-571. [CrossRef] [PubMed]

47. Keysers, C.; Diekamp, B.; Güntürkün, O. Evidence for physiological asymmetries in the intertectal connections of the pigeon (Columba livia) and their potential role in brain lateralisation. Brain Res. 2000, 852, 406-413. [CrossRef]

48. Genç, E.; Ocklenburg, S.; Singer, W.; Güntürkün, O. Abnormal interhemispheric motor interactions in patients with callosal agenesis. Behav. Brain Res. 2015, 293, 1-9. [CrossRef] [PubMed]

49. Bailey, C.H.; Kandel, E.R.; Harris, K.M. Structural components of synaptic plasticity and memory consolidation. Cold Spring Harb. Perspect. Biol. 2015, 7. [CrossRef] [PubMed]

50. Liedvogel, M.; Feender, G.; Wada, K.; Troje, N.F.; Jarvis, E.D.; Mouritsen, H. Lateralized activation of cluster $\mathrm{N}$ in the brain of migratory songbird. Eur. J. Neurosci. 2007, 25, 116-1173. [CrossRef] [PubMed]

51. Nottelmann, F.; Wohlschläger, A.; Güntürkün, O. Unihemispheric memory in pigeons-Knowledge, the left hemisphere is reluctant to share. Behav. Brain Res. 2002, 133, 309-315. [CrossRef]

52. Xiao, Q.; Güntürkünn, O. Natural split brains? Lateralized memory for task contingencies in pigeons. Neurosci. Lett. 2009, 458, 75-78. [CrossRef] [PubMed]

53. Vallortigara, G.; Rogers, L.J. Survival with an asymmetrical brain: Advantages and disadvantages of cerebral lateralization. Behav. Brain Sci. 2005, 28, 575-589. [CrossRef] [PubMed]

54. Zapka, M.; Heyers, D.; Liedvogel, M.; Jarvis, E.D.; Mouritsen, H. Night-time neuronal activation of cluster N in a day- and night-migration songbird. Eur. J. Neurosci. 2010, 32, 619-624. [CrossRef] [PubMed]

55. Nießner, C.; Ernst Strüngmann Institut, Frankfurt am Main, Germany. Personal communication, 2013.

56. Rogers, L.J. Light input and the reversal of functional lateralization in the chicken brain. Behav. Brain Res. 1990, 38, 211-221. [CrossRef] 
57. Manns, M.; Güntürkün, O. Monocular deprivation alters the direction of functional and morphological asymmetries in the pigeon's visual system. Behav. Neurosci. 1999, 113, 1-10. [CrossRef]

58. Skiba, M.; Diekamp, B.; Güntürkün, O. Embryonic light stimulation induces different asymmetries in visuoperceptual and visuomotor pathways of pigeons. Behav. Brain Res. 2002, 134, 149-156. [CrossRef]

59. Hausmann, M. Why sex hormones matter for neuroscience: A very short review on sex, sex hormones, and functional brain asymmetries. J. Neurosci. Res. 2017, 95, 40-49. [CrossRef] [PubMed]

60. Mouritsen, H.; Feender, G.; Hegemann, A.; Liedvogel, M. Thermopaer can replace typewriter correction paper in Emlen funnels. J. Ornithol. 2009, 150, 713-715. [CrossRef]

61. Wiltschko, R.; Thalau, P.; Gehring, D.; Nießner, C.; Ritz, T.; Wiltschko, W. Magnetoreception in birds: The effect of radio frequency fields. J. R. Soc. Interface 2015, 12, 20141103. [CrossRef] [PubMed]

(c) 2017 by the authors. Licensee MDPI, Basel, Switzerland. This article is an open access article distributed under the terms and conditions of the Creative Commons Attribution (CC BY) license (http:/ / creativecommons.org/licenses/by/4.0/). 